\title{
Time trends in dietary fat intake in a sample of German children and adolescents between 2000 and 2010: not quantity, but quality is the issue
}

\author{
Lars Libuda ${ }^{1 *}$, Ute Alexy $^{2}$ and Mathilde Kersting ${ }^{1}$ \\ ${ }^{1}$ Research Institute of Child Nutrition (FKE), Heinstueck 11, D-44225 Dortmund, Germany \\ ${ }^{2}$ IEL-Nutritional Epidemiology, University of Bonn, DONALD Study at the Research Institute of Child Nutrition, \\ Bonn, Germany \\ (Submitted 18 October 2012 - Final revision received 15 May 2013 - Accepted 24 May 2013 - First published online 8 July 2013)
}

\section{Abstract}

Dietary fat intake in childhood may influence the risk for developing chronic diseases. The objective of the present study was to examine secular trends in the parameters of fat intake between 2000 and 2010 in a sample of German children and adolescents ( $n$ 808) participating in the Dortmund Nutritional and Anthropometric Longitudinally Designed (DONALD) Study. Dietary data from $43803 \mathrm{~d}$ weighed dietary records were analysed using repeated-measures regression to determine time trends in fat quantity, i.e. the intake of total fat, and in fat quality, i.e. the ratios of SFA, MUFA and PUFA. In young children (2-3 years) and in adolescents (13-18 years), total fat intake remained stable over time, but decreased by $0.08 \%$ of total energy (\%E) per year in 4-12-year-old children. In 2010, median fat intake was at the upper end of the recommendations. SFA intake decreased slightly in 2-3- and 4-12-year-old children by 0.09 and $0.05 \% \mathrm{E}$ per year, respectively. MUFA and PUFA intakes remained stable in all the age groups except in adolescents. Here, PUFA intake decreased initially, but increased between 2005 and 2010. In 2010, only between 3 and 18\% of the respective age groups had an intake of SFA or PUFA within the recommendations. In conclusion, fat quantity and quality did not change substantially between 2000 and 2010 . Fat quality, in particular, needs to be improved, since a large percentage of our sample did not meet the recommended intakes for SFA and PUFA.

\section{Key words: Fat intake: Fat quality: Trends: Time: Secular trends}

Dietary fat is known to play a role in the pathogenesis of several chronic diseases such as cancer, type 2 diabetes mellitus and CVD. At least for the latter, the quality of dietary fat, i.e. the ratios of SFA, MUFA and PUFA, seems to be more relevant than the total amount of dietary fat intake ${ }^{(1)}$. Accordingly, a pooled analysis of data from eleven cohort studies revealed that a dietary pattern with a low ratio of SFA:PUFA is associated with lower rates of coronary events in adults ${ }^{(2)}$. In 2010, an expert panel of the WHO concluded that there is strong evidence for a reduced risk of CVD when SFA are replaced by MUFA or PUFA ${ }^{(1)}$. In contrast, the replacement of SFA by carbohydrates does not seem to have a protective effect $^{(3)}$. Studies in childhood point to a beneficial effect of an improvement of fat quality on the levels of total cholesterol and LDL-cholesterol ${ }^{(4,5)}$, both of which are known to be risk factors of CVD in adulthood. As elevated cholesterol levels, and dietary patterns more generally, might be sustained from childhood into adulthood, improvements in children's fat intake might be one effective approach for the prevention of nutrition-related chronic diseases such as CVD.
The dietary recommendations of several authorities take into account both aspects of dietary fat intake: quantity and quality. Regarding fat quantity, i.e. the amount of total fat, the German Nutrition Society (DGE) has recommended a total fat intake of $30-40 \%$ of energy (\%E) for children between 1 and 3 years of age, a range of 30-35\%E for children between 4 and 14 years of age and a total fat intake $\leq 30 \%$ E for adolescents and adults. With regard to fat quality, the DGE generally recommends a SFA intake $\leq 10 \% \mathrm{E}$ and a PUFA intake $\geq 7 \% \mathrm{E}$ for all age groups without explicitly distinguishing between children and adolescents ${ }^{(6)}$. A reduction in SFA intake to a maximum of $10 \% \mathrm{E}$ is also currently the aim of the Dietary Guidelines for Americans including children and adolescents ${ }^{(7)}$. In contrast, the European Food Safety Authority (EFSA) ${ }^{(8)}$ does not formulate a dietary reference value for SFA, but recommends that SFA intake should be as low as possible.

Although dietary recommendations and public health initiatives stress the importance of dietary fat quantity and quality, the actual intake of children and adolescents rarely meets these guidelines. A comparison of national dietary

Abbreviations: \%E, percentage of total energy; DONALD, Dortmund Nutritional and Anthropometric Longitudinally Designed; TEI, total energy intake.

*Corresponding author: Dr L. Libuda, fax +49 23171 15 81; email libuda@fke-do.de 
surveys from thirty countries on fat intake in childhood and adolescence has revealed mean intakes for SFA above and for PUFA below the recommendations in nearly all countries $^{(9)}$. The Healthy Lifestyle in Europe by Nutrition in Adolescence (HELENA) study on European adolescents between 12.5 and 17.5 years of age has also revealed intakes of PUFA below and SFA above the recommendations in most adolescents, with mean intakes of $4.4 \% \mathrm{E}(4.8 \% \mathrm{E})$ in males (females) for PUFA and $13.8 \% \mathrm{E}(13.9 \% \mathrm{E})$ for $\mathrm{SFA}^{(10)}$. However, due to their cross-sectional design, these data are not appropriate for evaluating the effectiveness of public health initiatives to improve fat intake. In the case of carbohydrates, a recent analysis of the Dortmund Nutritional and Anthropometric Longitudinally Designed (DONALD) Study has observed that, in addition to an increase in $\% \mathrm{E}$ from carbohydrates, there was a negative time trend, i.e. a worsening of carbohydrate quality, in German adolescents between 1988 and 2007. This deterioration was characterised by increasing intakes of added sugars from sources other than sweets or soft drinks and by decreasing fibre intakes ${ }^{(11)}$. These findings might raise concern as to whether the declining carbohydrate quality is accompanied by similar trends in fat intake.

The main objective of the present analysis of data from the DONALD Study was, therefore, to analyse secular trends in fat quantity and quality in three age groups (2-3, 4-12 and 13-18 years) between 2000 and 2010. Furthermore, in order to get an insight into potential approaches for improving fat intake, changes in the intake of major food sources of dietary fat were analysed.

\section{Methods}

\section{Study design}

The DONALD Study is an ongoing open cohort study that started in 1985 at the Research Institute of Child Nutrition in Dortmund, Germany. Its aim is to investigate the relationship between nutrition, development, metabolism and hormonal status during childhood and adolescence. Healthy newborns from Dortmund and surrounding communities are recruited at the age of 3 months. The regular assessments begin at 3 months of age and take place annually from the age of 2 years onwards. According to the study protocol, these assessments include a $3 \mathrm{~d}$ weighed dietary record, anthropometric and medical assessments and, beginning at 3 years of age, collection of a $24 \mathrm{~h}$ urine sample. Further details of the DONALD Study design have been described elsewhere ${ }^{(12)}$. Since the beginning of the DONALD Study, about forty to fifty subjects have been newly enrolled every year. This open design of the DONALD Study enables the separation of time trends from age-related changes in food and nutrient intakes.

For the present analysis, we examined information from $3 \mathrm{~d}$ dietary records ( $n$ 4804) collected between 2000 and 2010 for participants between 2 and 18 years of age. Of those, only records with plausible information on total energy intake (TEI) were included in the data analysis. Plausibility was assessed by applying age- and sex-specific cut-offs for the ratio of reported TEI:individual BMR, which was calculated with equations that use individual body weight and height $^{(13)}$. Body weight was measured to the nearest $0 \cdot 1 \mathrm{~kg}$ using an electronic scale (Seca 753 E; Seca GmbH \& Co. $\mathrm{KG}$ ), and height was measured in a standing position to the nearest $0 \cdot 1 \mathrm{~cm}$ using a digital telescopic stadiometer (Harpenden; Holtain Limited). According to Sichert-Hellert et al. ${ }^{(14)}$, TEI/BMR cut-offs are 0.97 for boys and girls until the age of 5 years, 1.04 (1.01) for boys (girls) aged 6-13 years and 1.07 (0.97) for boys (girls) aged 14-18 years. Of the $3 \mathrm{~d}$ records, two records had to be excluded due to missing anthropometric data for the BMR calculation and 422 records were excluded due to implausibility.

This selection resulted in $43803 \mathrm{~d}$ dietary records from 808 subjects (406 boys). The individual number of $3 \mathrm{~d}$ records per subject ranged from 1 ( $n$ 98) to 11 ( $n$ 67), mean 5.4 records per subject. Mean ages at the first dietary record considered in the present analysis were 5.9 (SD 4.9) years in boys and 6.1 (SD 5.0) years in girls. In order to separate trends over time from age trends, we decided to choose an open design for each age group, i.e. subjects were not assigned to a fixed age stratum according to their age in the year 2000, but might be considered in more than one age stratum during the examination period.

\section{Ethical approval}

The DONALD Study has been conducted according to the guidelines laid down in the Declaration of Helsinki and has been approved by the ethical committee of the University of Bonn, Germany. All assessments are performed with parental and, for older children, with the children's written informed consent.

\section{Dietary recording and nutritional outcomes}

For dietary recording, all foods and beverages before consumption, as well as any leftovers, were weighed and recorded by the parents of the children or by the older subjects themselves on three consecutive days. The proportions of records with self-reporting (assisting in reporting) by the children themselves were $0.0 \%(0 \cdot 1 \%), 2 \cdot 2 \%(46 \cdot 8 \%)$ and $53.7 \%(46 \cdot 0 \%)$ in $2-3,4-12$ and $13-18$-year-old subjects. The participants chose the day on which they began dietary recording within a given period of time. Semi-quantitative recording (e.g. numbers of glasses and cups) was allowed, if weighing was not possible.

Individual intakes of energy, nutrients and food groups were calculated as arithmetic means of the three recorded days using the in-house nutrient database LEBTAB $^{(15)}$, which contains detailed data on the energy and nutrient content of all the recorded food items (currently about 12600) and is continuously updated. Information on the nutrient content of basic foods, e.g. milk, fruit, vegetables and meat, was taken from standard nutrient tables; the content of commercial foods, e.g. cold meats and ready-to-eat foods, was calculated by simulating recipes from labelled ingredients and nutrients.

For the present analysis, we calculated the individual intake for the following parameters (in $\mathrm{g}$ and $\% \mathrm{E}$ ): total 


\section{N British Journal of Nutrition}

Table 1. Trends in energy and fat intakes in 2-18-year-old participants of the Dortmund Nutritional and Anthropometric Longitudinally Designed (DONALD) Study, 2000 and 2010* (Medians and interquartile ranges (IQR: quartile 1-quartile 3))

\begin{tabular}{|c|c|c|c|c|c|c|c|c|c|c|c|c|}
\hline \multirow[b]{2}{*}{ Outcome } & \multicolumn{2}{|c|}{2000} & \multicolumn{2}{|c|}{2010} & \multicolumn{2}{|c|}{ Time } & \multicolumn{2}{|c|}{ Time $^{2}$} & \multicolumn{2}{|c|}{ Age } & \multicolumn{2}{|c|}{$\mathrm{Age}^{2}$} \\
\hline & Median & IQR & Median & IQR & $\beta$ & $P$ & $\beta$ & $P$ & $\beta$ & $P$ & $\beta$ & $P$ \\
\hline \multicolumn{13}{|c|}{ Age: $2-3$ years ( 221 boys and 206 girls, 714 dietary records) } \\
\hline Energy $(\mathrm{MJ} / \mathrm{d})$ & 4.1 & $3.7-4.7$ & $4 \cdot 1$ & $3.7-4.5$ & -0.0006 & 0.950 & & & 0.605 & $<0.001$ & & \\
\hline \multicolumn{13}{|l|}{ Carbohydrates } \\
\hline$g / d$ & $124 \cdot 0$ & $108 \cdot 4-153.9$ & $128 \cdot 1$ & $108 \cdot 9-145 \cdot 3$ & -0.101 & 0.772 & & & $21 \cdot 845$ & $<0.001$ & & \\
\hline$\% \mathrm{E}$ & $52 \cdot 1$ & $46 \cdot 1-56 \cdot 2$ & $52 \cdot 3$ & $46 \cdot 6-56 \cdot 5$ & -0.024 & 0.783 & & & $1 \cdot 159$ & 0.002 & & \\
\hline \multicolumn{13}{|l|}{ Protein } \\
\hline$g / d$ & $33 \cdot 2$ & $28 \cdot 6-37 \cdot 3$ & 34.0 & $29 \cdot 5-38.2$ & 0.265 & 0.009 & & & $2 \cdot 741$ & 0.001 & & \\
\hline$\% \mathrm{E}$ & $13 \cdot 3$ & $11 \cdot 7-14.9$ & $13 \cdot 8$ & $12 \cdot 1-15 \cdot 2$ & 0.105 & 0.001 & & & -0.766 & $<0.001$ & & \\
\hline \multicolumn{13}{|l|}{ Total fat } \\
\hline$g / d$ & $37 \cdot 8$ & $32 \cdot 7-44.5$ & $37 \cdot 2$ & $30 \cdot 3-44 \cdot 3$ & -0.072 & 0.557 & & & 5.080 & $<0.001$ & & \\
\hline$\% \mathrm{E}$ & 33.9 & $31 \cdot 7-39.8$ & 34.6 & $30 \cdot 5-38.5$ & -0.072 & 0.352 & & & -0.389 & 0.252 & & \\
\hline \multicolumn{13}{|l|}{ SFA } \\
\hline$g / d$ & $17 \cdot 4$ & $14 \cdot 3-22 \cdot 0$ & $15 \cdot 9$ & $13 \cdot 2-20 \cdot 3$ & -0.096 & 0.123 & & & $2 \cdot 144$ & $<0.001$ & & \\
\hline$\% \mathrm{E}$ & $15 \cdot 8$ & $13 \cdot 7-18 \cdot 1$ & $15 \cdot 2$ & $13 \cdot 0-16 \cdot 9$ & -0.089 & 0.028 & & & -0.295 & 0.207 & & \\
\hline \multicolumn{13}{|l|}{ MUFA } \\
\hline$g / d$ & $15 \cdot 4$ & $13.5-18.3$ & $15 \cdot 7$ & $12 \cdot 5-19.4$ & 0.004 & 0.946 & & & 2.035 & $<0.001$ & & \\
\hline$\% \mathrm{E}$ & $14 \cdot 3$ & $12 \cdot 7-16 \cdot 5$ & $14 \cdot 7$ & $12 \cdot 3-16 \cdot 6$ & -0.001 & 0.989 & & & 0.242 & 0.143 & & \\
\hline \multicolumn{13}{|l|}{ PUFA } \\
\hline$g / d$ & 4.9 & $4 \cdot 2-5 \cdot 9$ & $5 \cdot 0$ & $3 \cdot 7-6 \cdot 3$ & 0.019 & 0.406 & & & 0.903 & $<0.001$ & & \\
\hline$\% \mathrm{E}$ & 4.4 & $3 \cdot 5-5 \cdot 6$ & 4.5 & $3 \cdot 5-5 \cdot 8$ & 0.017 & 0.389 & & & 0.150 & 0.123 & & \\
\hline \multicolumn{13}{|c|}{ Age: $4-12$ years (296 boys and 285 girls, 2524 dietary records) } \\
\hline Energy $(\mathrm{MJ} / \mathrm{d})$ & $6 \cdot 3$ & $5 \cdot 4-7 \cdot 4$ & 6.5 & $5.5-7.6$ & 0.005 & 0.603 & & & 0.556 & $<0.001$ & & \\
\hline \multicolumn{13}{|l|}{ Carbohydrates } \\
\hline$g / d$ & $194 \cdot 2$ & $164 \cdot 7-233 \cdot 3$ & 201.9 & $173 \cdot 6-240 \cdot 5$ & 0.170 & 0.624 & & & 11.457 & $<0.001$ & & \\
\hline$\% \mathrm{E}$ & 52.4 & $48.5-56.0$ & 53.3 & $49 \cdot 4-57 \cdot 3$ & 0.022 & 0.615 & & & -0.028 & 0.573 & & \\
\hline \multicolumn{13}{|l|}{ Protein } \\
\hline $\mathrm{g} / \mathrm{d}$ & $47 \cdot 0$ & $39 \cdot 1-57 \cdot 1$ & 49.4 & $40 \cdot 8-58 \cdot 3$ & 0.251 & 0.003 & & & 3.300 & $<0.001$ & -0.026 & 0.422 \\
\hline$\% \mathrm{E}$ & $12 \cdot 6$ & $11 \cdot 3-13.9$ & $12 \cdot 8$ & $11 \cdot 5-14 \cdot 3$ & 0.060 & $<0.001$ & & & -0.207 & 0.038 & 0.015 & 0.016 \\
\hline \multicolumn{13}{|l|}{ Total fat } \\
\hline$g / d$ & 59.7 & $50 \cdot 3-71 \cdot 2$ & $59 \cdot 1$ & $44.6-69 \cdot 9$ & -0.062 & 0.561 & & & $3 \cdot 310$ & $<0.001$ & & \\
\hline$\% \mathrm{E}$ & $35 \cdot 0$ & $31 \cdot 7-38.5$ & $33 \cdot 8$ & $30 \cdot 3-37 \cdot 1$ & -0.083 & 0.036 & & & 0.003 & 0.941 & & \\
\hline SFA & & & & & & & & & & & & \\
\hline$g / d$ & $26 \cdot 3$ & $21.9-31.4$ & 25.9 & $19 \cdot 7-31 \cdot 4$ & -0.051 & 0.337 & & & 1.349 & $<0.001$ & & \\
\hline$\% \mathrm{E}$ & $15 \cdot 7$ & $13 \cdot 7-17 \cdot 4$ & $14 \cdot 8$ & $12 \cdot 9-16 \cdot 6$ & -0.053 & 0.014 & & & -0.067 & 0.006 & & \\
\hline MUFA & & & & & & & & & & & & \\
\hline$g / d$ & 24.5 & $20 \cdot 0-29 \cdot 0$ & 23.7 & $18.4-29.5$ & -0.020 & 0.668 & & & 1.370 & $<0.001$ & & \\
\hline$\% \mathrm{E}$ & $14 \cdot 3$ & $12 \cdot 7-16 \cdot 1$ & $13 \cdot 7$ & $12 \cdot 2-15 \cdot 4$ & 0.031 & 0.097 & & & 0.007 & 0.731 & & \\
\hline PUFA & & & & & & & & & & & & \\
\hline$g / d$ & $8 \cdot 3$ & $6 \cdot 4-10 \cdot 9$ & $8 \cdot 0$ & $6 \cdot 1-10 \cdot 3$ & 0.009 & 0.673 & & & 0.595 & $<0.001$ & & \\
\hline$\% \mathrm{E}$ & 4.8 & $4 \cdot 0-5 \cdot 8$ & 4.7 & $3 \cdot 8-5 \cdot 7$ & -0.0002 & 0.983 & & & 0.066 & $<0.001$ & & \\
\hline Age: $13-18$ years & 2 boys an & 5 girls, 1142 die & records) & & & & & & & & & \\
\hline Energy $(\mathrm{MJ} / \mathrm{d})$ & $9 \cdot 1$ & $7 \cdot 5-10 \cdot 3$ & $8 \cdot 7$ & $7 \cdot 3-10 \cdot 2$ & -0.021 & 0.421 & & & $2 \cdot 12$ & $<0.001$ & -0.060 & $<0.001$ \\
\hline Carbohydrates & & & & & & & & & & & & \\
\hline$g / d$ & $273 \cdot 2$ & $221.6-328.0$ & 271.9 & $221 \cdot 3-321 \cdot 3$ & 3.782 & 0.108 & -0.489 & 0.023 & 6.372 & $<0.001$ & & \\
\hline$\% \mathrm{E}$ & 51.0 & $46 \cdot 2-55 \cdot 4$ & 51.7 & $48 \cdot 7-55.7$ & 0.385 & 0.075 & -0.043 & 0.031 & -0.220 & 0.039 & & \\
\hline Protein & & & & & & & & & & & & \\
\hline$g / d$ & 68.5 & $58.9-81.9$ & $70 \cdot 0$ & $58 \cdot 3-82 \cdot 6$ & 0.097 & 0.710 & & & 2.474 & $<0.001$ & & \\
\hline$\% \mathrm{E}$ & $12 \cdot 9$ & $11.7-14.7$ & $13 \cdot 1$ & $11 \cdot 8-14.6$ & 0.055 & 0.037 & & & 0.069 & 0.058 & & \\
\hline
\end{tabular}


carbohydrates; total protein; total fat, SFA, MUFA and PUFA. We also calculated the individual total fat intake (\%) from the following food groups, which have a substantial fat content: 'milk and milk products' (including cheese); 'fats and oils' (including butter, margarine and vegetable oils); 'meat, meat products and eggs'; 'fish and fish products'; 'nuts and seeds'; 'candy' (including cakes and pastries); 'sauces' (including mayonnaise, remoulade and salad cream); 'convenience and fast foods' (including ready-to-eat meals, pizzas, burgers and kebabs, but not including sauces, soups and frozen vegetables).

\section{Statistical analyses}

All statistical analyses were performed using SAS ${ }^{\circledR}$ procedures (version 9.2; SAS Institute). A $P$ value $<0.05$ was considered significant. Descriptive data at the beginning and end of the examination period are presented as median and interquartile ranges.

Secular trend analyses over the 10-year observation period stratified by age groups $(2-3,4-12$ and $13-18$ years) were performed using repeated-measures regression analyses (PROC MIXED) including both a fixed and a random statement. Separate models considered TEI, total fat, SFA, MUFA or PUFA, total carbohydrates or total protein, as the outcome variable. As interaction analyses did not reveal any differences in secular trends between boys and girls for any of the fat parameters, we decided to use pooled data for all the analyses. A repeated statement with an exponential spatial structure of covariance was used to account for the lack of independence between repeated measures on the same subject. The random statement considered individual differences in the baseline value of the respective outcome variable.

Since recommendations for fat intake are generally given as $\% \mathrm{E}$, we focused on these values for model development. However, Chanmugam et al. ${ }^{(16)}$ observed that time trends in fat intake might be masked when only presented as \% $\mathrm{E}$ without further information on changes in TEI and absolute fat intake in grams. Therefore, we also analysed time trends in absolute intake of fat parameters using a model that was the same as that used for the respective fat parameter in \%E. The basic model included the variables time (years since the first included record in the evaluation) and chronological age (years) as the principal fixed effects. Quadratic terms for age and time and a cubic term for time were included as additional explanatory variables if they significantly predicted the respective outcome variable or improved the fit statistic (Akaike's information criterion) by more than two points. In case of a significant linear time trend, the increase or decrease of the respective outcome variable is constant in every year. In contrast, quadratic and cubic time trends indicate that the respective outcome variable changes little in the first few years, but the changes accelerate later on. The approach used for model development in the case of fat was also used to examine trends in food intake. Separate models were developed for fat intake (\%E) from the respective food group and the absolute food group intake (in $\mathrm{g} / \mathrm{d}$ ) as outcome variables. 
Table 2. Percentage of participants from the Dortmund Nutritional and Anthropometric Longitudinally Designed (DONALD) Study meeting the respective recommendations for fat intake*

\begin{tabular}{|c|c|c|c|c|c|c|}
\hline & \multicolumn{3}{|c|}{2000} & \multicolumn{3}{|c|}{2010} \\
\hline & $2-3$ years $(n 73)$ & $4-12$ years $(n 224)$ & $13-18$ years $(n 96)$ & $2-3$ years $(n 66)$ & $4-12$ years $(n 228)$ & $13-18$ years $(n 98)$ \\
\hline Total fat (\%) & $60 \cdot 3$ & $33 \cdot 2$ & $23 \cdot 2$ & $62 \cdot 1$ & $38 \cdot 0$ & $31 \cdot 0$ \\
\hline SFA $(\%)$ & 2.8 & 2.6 & 4.0 & $6 \cdot 1$ & 3.0 & 8.0 \\
\hline PUFA (\%) & $8 \cdot 2$ & $9 \cdot 6$ & $22 \cdot 2$ & $12 \cdot 1$ & $7 \cdot 7$ & $18 \cdot 0$ \\
\hline
\end{tabular}

* Total fat: $30-40 \% E$ for 1 - to 3 -year-olds, $30-35 \% E$ for 4 - to 14 -year-olds and $\leq 30 \% E$ for $15-19$-year-old adolescents; SFA: $\leq 10 \% E$ for all the age groups; PUFA: $\geq 7 \% E$ for all the age groups.

\section{Results \\ Dietary fat intake in 2010 compared with recommendations}

In 2010, median fat intake in the examined age groups ranged between 33.8 and $34.6 \% \mathrm{E}$ and was, therefore, well within the recommended range, at least in children (Table 1). On an individual level, a large percentage of the study sample did not meet the recommendations for total fat intake. In the case of SFA and PUFA, nearly all the participants did not meet the recommendations (Table 2).

\section{Trends in fat intake}

Between 2000 and 2010, neither TEI nor absolute intake of any fat parameters changed significantly in any age stratum (Table 1). There was also no significant change in total fat intake in $\% \mathrm{E}$ during the 10 -year period in 2- to 4-year-old children, but a slight decrease by about $0.08 \% \mathrm{E}$ per year was observed in 4- to 12-year-old children. Fig. 1 illustrates the change in total fat intake in adolescents as an example of a combination of opposing linear and quadratic time trends. In the oldest age group, opposing linear and quadratic time trends, resulting in decreasing intakes of total fat until 2005 and increasing fat intakes afterwards, were observed (Fig. 1). Between 2000 and 2010, protein intake (\%E) increased slightly in every age group, while carbohydrate intake $(\% \mathrm{E})$ did not change uniformly.

Between 2000 and 2010, significant changes in fatty acid intake were observed for some parameters given as $\% \mathrm{E}$, but not for absolute intakes $(\mathrm{g} / \mathrm{d})$. SFA intake as \%E decreased slightly in 2-3- and 4-12-year-old children. MUFA and PUFA intakes ( $\mathrm{g}$ and \%E) remained stable in all the age groups except for $\% \mathrm{E}$ from PUFA in adolescents. This parameter developed parallel to total fat intake, i.e. revealed an initial decline due to a negative linear trend, which was compensated by a positive quadratic trend at the end of the examination period.

\section{Trends in fat sources}

In all the age groups, milk and milk products, fats and oils, meat and meat products, and candy were the main contributors to total fat intake in both 2000 and 2010. Fat intake from milk and milk products decreased between 2000 and 2010 from $8 \cdot 6-9 \cdot 9 \%$ E to $6 \cdot 4-8.8 \% E$ (Table 3). Simultaneously, fat intake from oils declined linearly in all the age groups.
In 4-12- and 13-18-year-old subjects, this initial decline in fat intake from oils was attenuated at the end of the examination period. The decreasing intakes of fat from milk and oils were at least partly compensated by increases in fat intake from convenience foods and fast foods in $2-3$ - and 15-18-year-old participants and from sauces in 4-12-year-old children. Despite a small increase in fat intake from fish in 4-12-year-old children and in adolescents, the fat intake from food groups with a high fat quality (e.g. nuts and fish) was continuously low $(<1 \% \mathrm{E})$.

\section{Discussion}

The main finding of the present analysis was that both fat quantity and quality did not change substantially in a sample of German children and adolescents between 2000 and 2010. Total fat intake either remained stable over time (in the youngest children and in adolescents) or decreased only slightly (0.08\%E per annum in 4-12-year-old children), while protein intake increased in every age group. In 2010, median fat intake was at the upper end of the recommendations $(30-40 \% \mathrm{E}$ for 1 - to 3-year-olds, 30-35\% E for $4-$ to 14 -year-olds, and $\leq 30 \% \mathrm{E}$ for adolescents aged 15 years or above). At the same time, we observed only a slight decrease

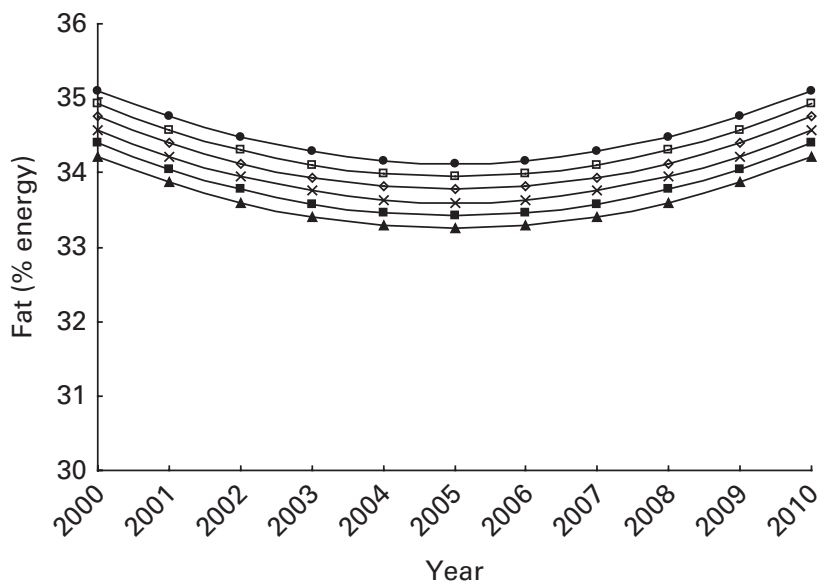

Fig. 1. Predicted time and age trends in the intake of dietary fat in 13- to 18-year-old male and female participants of the Dortmund Nutritional and Anthropometric Longitudinally Designed (DONALD) Study between the years 2000 and 2010 resulting from a mixed linear model as an example of a combination of opposing linear and quadratic time trends. The course of the six parallel curves represents the isolated time trend. The constant vertical differences represent the isolated age trend. •, 13-year-olds; $\square$, 14-year-olds; $\diamond$, 15-year-olds; $\times$, 16-year-olds; $\mathbf{\square}, 17$-year-olds; $\boldsymbol{\Lambda}$, 18-year-olds. 


\section{N British Journal of Nutrition}

Table 3. Trends in food group intake in 2-18-year-old participants of the Dortmund Nutritional and Anthropometric Longitudinally Designed (DONALD) Study, 2000 and 2010*

(Medians and interquartile ranges (IQR: quartile 1-quartile 3))

\begin{tabular}{|c|c|c|c|c|c|c|c|c|c|c|c|c|c|c|}
\hline \multirow[b]{2}{*}{ Food group } & \multicolumn{2}{|c|}{2000} & \multicolumn{2}{|c|}{2010} & \multicolumn{2}{|c|}{ Time } & \multicolumn{2}{|c|}{ Time $^{2}$} & \multicolumn{2}{|c|}{ Time $^{3}$} & \multicolumn{2}{|c|}{ Age } & \multicolumn{2}{|c|}{$\mathrm{Age}^{2}$} \\
\hline & Median & IQR & Median & IQR & $\beta$ & $P$ & $\beta$ & $P$ & $\beta$ & $P$ & $\beta$ & $P$ & $\beta$ & $P$ \\
\hline \multicolumn{15}{|c|}{ Age: $2-3$ years (221 boys and 206 girls, 714 dietary records) } \\
\hline \multicolumn{15}{|l|}{ Milk } \\
\hline Fat in \%E & 9.9 & $6 \cdot 3-14 \cdot 8$ & $8 \cdot 8$ & $4.9-11 \cdot 6$ & -0.189 & 0.009 & & & & & -1.561 & $<0.001$ & & \\
\hline$g / d$ & 283.8 & $173 \cdot 7-374.4$ & $228 \cdot 6$ & $134 \cdot 9-356 \cdot 0$ & $-1 \cdot 150$ & 0.633 & & & & & -9.318 & 0.308 & & \\
\hline \multicolumn{15}{|l|}{ Oils } \\
\hline Fat in \%E & 5.4 & $2 \cdot 7-8 \cdot 0$ & 3.5 & $1 \cdot 8-5 \cdot 8$ & -0.135 & 0.003 & & & & & 0.044 & 0.832 & & \\
\hline$g / d$ & 8.0 & $4 \cdot 1-12 \cdot 0$ & 5.5 & $2 \cdot 4-8 \cdot 6$ & -0.182 & 0.003 & & & & & 0.986 & 0.012 & & \\
\hline \multicolumn{15}{|l|}{ Meat } \\
\hline Fat in $\% E$ & $7 \cdot 6$ & $4 \cdot 7-12 \cdot 8$ & $7 \cdot 3$ & $3 \cdot 4-12 \cdot 0$ & -0.011 & 0.876 & & & & & 0.118 & 0.695 & & \\
\hline$g / d$ & 43.1 & $31 \cdot 7-61.5$ & $44 \cdot 8$ & $28 \cdot 0-63 \cdot 7$ & -0.080 & 0.819 & & & & & 7.463 & $<0.001$ & & \\
\hline \multicolumn{15}{|l|}{ Fish } \\
\hline Fat in \%E & 0.0 & $0.0-0.4$ & 0.0 & $0.0-0.2$ & 0.011 & 0.347 & & & & & -4.898 & 0.001 & 0.979 & 0.001 \\
\hline$g / d$ & 0.0 & $0.0-10 \cdot 0$ & 0.0 & $0.0-7 \cdot 0$ & 0.090 & 0.553 & & & & & -55.992 & 0.004 & 11.300 & 0.003 \\
\hline \multicolumn{15}{|l|}{ Nuts } \\
\hline Fat in $\% \mathrm{E}$ & 0.0 & $0.0-0.4$ & 0.0 & $0.0-0.0$ & -0.001 & 0.910 & & & & & 0.145 & 0.015 & & \\
\hline$g / d$ & 0.0 & $0.0-0.9$ & 0.0 & $0.0-0.0$ & 0.015 & 0.675 & & & & & 0.445 & 0.003 & & \\
\hline \multicolumn{15}{|l|}{ Candy } \\
\hline Fat in \%E & 3.7 & $2 \cdot 0-5 \cdot 8$ & 4.0 & $1.5-7.9$ & 0.072 & 0.111 & & & & & 1.503 & $<0.001$ & & \\
\hline$g / d$ & $29 \cdot 3$ & $20 \cdot 0-50 \cdot 8$ & $37 \cdot 0$ & $19 \cdot 2-70 \cdot 5$ & 0.655 & 0.081 & & & & & $16 \cdot 039$ & $<0.001$ & & \\
\hline \multicolumn{15}{|l|}{ Sauces } \\
\hline Fat in $\%$ E & 0.0 & $0.0-0.1$ & 0.1 & $0.0-0.3$ & 0.008 & 0.428 & & & & & 0.181 & 0.002 & & \\
\hline$g / d$ & 0.4 & $0.0-3 \cdot 4$ & 1.9 & $0.1-9.4$ & 0.110 & 0.277 & & & & & 1.720 & $<0.001$ & & \\
\hline $\mathrm{CF}$ & & & & & & & & & & & & & & \\
\hline Fat in \%E & 0.0 & $0.0-0.8$ & 0.3 & $0.0-1.3$ & 0.045 & 0.027 & & & & & 0.213 & 0.071 & & \\
\hline$g / d$ & 0.0 & $0 \cdot 0-17 \cdot 0$ & 9.5 & $0 \cdot 0-30 \cdot 8$ & 0.957 & 0.002 & & & & & $4 \cdot 123$ & 0.017 & & \\
\hline Age: $4-12$ year & 296 boys & dd 285 girls, 252 & dietary $r \in$ & rds) & & & & & & & & & & \\
\hline Milk & & & & & & & & & & & & & & \\
\hline Fat in $\% E$ & 8.6 & $5 \cdot 7-11 \cdot 0$ & $6 \cdot 4$ & $4 \cdot 2-9 \cdot 0$ & -0.157 & $<0.001$ & & & & & -0.092 & 0.007 & & \\
\hline$g / d$ & $305 \cdot 3$ & $193 \cdot 1-415 \cdot 5$ & $240 \cdot 6$ & $154 \cdot 1-363 \cdot 3$ & $2 \cdot 176$ & 0.392 & -0.045 & 0.043 & & & 6.419 & $<0.001$ & & \\
\hline Oils & & & & & & & & & & & & & & \\
\hline Fat in \%E & $6 \cdot 0$ & $3.8-8.0$ & 4.4 & $2 \cdot 7-7 \cdot 1$ & -0.353 & $<0.001$ & 0.028 & 0.0001 & & & -0.076 & 0.010 & & \\
\hline$g / d$ & $12 \cdot 2$ & $7 \cdot 8-18 \cdot 0$ & $9 \cdot 2$ & $5 \cdot 6-14.9$ & $-1 \cdot 312$ & $<0.001$ & 0.208 & 0.014 & -0.009 & 0.089 & 1.352 & $<0.001$ & -0.059 & 0.011 \\
\hline Meat & & & & & & & & & & & & & & \\
\hline Fat in \%E & 6.9 & $4.0-10 \cdot 4$ & $7 \cdot 3$ & $3.9-10.5$ & 0.016 & 0.622 & & & & & -0.094 & 0.012 & & \\
\hline$g / d$ & 71.9 & $47 \cdot 2-102 \cdot 3$ & $72 \cdot 0$ & $44.0-99.9$ & -1.680 & 0.052 & 0.180 & 0.027 & & & 4.076 & $<0.001$ & & \\
\hline Fish & & & & & & & & & & & & & & \\
\hline Fat in \%E & 0.0 & $0.0-0.4$ & 0.0 & $0.0-0.3$ & 0.033 & 0.018 & & & -0.0003 & 0.017 & -0.006 & 0.432 & & \\
\hline$g / d$ & 0.0 & $0.0-18 \cdot 4$ & 0.0 & $0.0-10 \cdot 6$ & 0.003 & 0.980 & & & & & 0.482 & 0.001 & & \\
\hline Nuts & & & & & & & & & & & & & & \\
\hline Fat in \%E & 0.0 & $0.0-0.4$ & 0.0 & $0.0-0.0$ & 0.003 & 0.720 & & & & & -0.106 & 0.072 & 0.006 & 0.079 \\
\hline$g / d$ & 0.0 & $0.0-1 \cdot 2$ & 0.0 & $0.0-0.0$ & -0.209 & 0.024 & 0.023 & 0.010 & & & 0.070 & 0.024 & & \\
\hline Candy & & & & & & & & & & & & & & \\
\hline Fat in \%E & $6 \cdot 1$ & $3.6-8.3$ & $6 \cdot 2$ & $3 \cdot 8-10 \cdot 1$ & 0.027 & 0.374 & & & & & 0.103 & 0.003 & & \\
\hline$g / d$ & 69.4 & $50 \cdot 7-100 \cdot 0$ & $75 \cdot 7$ & $52 \cdot 7-111 \cdot 0$ & 0.512 & 0.147 & & & & & $10 \cdot 731$ & $<0.001$ & -0.412 & 0.006 \\
\hline Sauces & & & & & & & & & & & & & & \\
\hline Fat in $\% \mathrm{E}$ & 0.1 & $0.0-0.5$ & 0.1 & $0.0-0.7$ & 0.111 & $<0.001$ & -0.010 & $<0.001$ & & & 0.060 & $<0.001$ & & \\
\hline$g / d$ & 5.0 & $0 \cdot 7-12 \cdot 0$ & 6.9 & $1.4-15.4$ & 0.204 & 0.083 & & & & & 1.334 & $<0.001$ & & \\
\hline $\mathrm{CF}$ & & & & & & & & & & & & & & \\
\hline Fat in \%E & 0.3 & $0 \cdot 0-2 \cdot 2$ & 0.5 & $0.0-2 \cdot 7$ & 0.023 & 0.124 & & & & & 0.133 & $<0.001$ & & \\
\hline$g / d$ & $20 \cdot 0$ & $0 \cdot 0-45 \cdot 7$ & $21 \cdot 2$ & $0.0-73 \cdot 3$ & 0.440 & 0.209 & & & & & $5 \cdot 155$ & $<0.001$ & & \\
\hline
\end{tabular}


Table 3. Continued

\begin{tabular}{|c|c|c|c|c|c|c|c|c|c|c|c|c|c|c|}
\hline \multirow[b]{2}{*}{ Food group } & \multicolumn{2}{|c|}{2000} & \multicolumn{2}{|c|}{2010} & \multicolumn{2}{|c|}{ Time } & \multicolumn{2}{|c|}{ Time $^{2}$} & \multicolumn{2}{|c|}{ Time $^{3}$} & \multicolumn{2}{|c|}{ Age } & \multicolumn{2}{|c|}{$\mathrm{Age}^{2}$} \\
\hline & Median & IQR & Median & IQR & $\beta$ & $P$ & $\beta$ & $P$ & $\beta$ & $P$ & $\beta$ & $P$ & $\beta$ & $P$ \\
\hline \multirow{2}{*}{\multicolumn{15}{|c|}{$\begin{array}{l}\text { Age: } 13-18 \text { years (172 boys and } 175 \text { girls, } 1142 \text { dietary records) } \\
\text { Milk }\end{array}$}} \\
\hline & & & & \multicolumn{11}{|c|}{ Milk } \\
\hline Fat in $\% \mathrm{E}$ & 8.7 & $6 \cdot 0-12 \cdot 0$ & $7 \cdot 2$ & $4 \cdot 1-10 \cdot 2$ & -0.353 & 0.012 & 0.023 & 0.085 & & & 0.054 & 0.431 & & \\
\hline$g / d$ & $370 \cdot 9$ & $238 \cdot 7-578 \cdot 2$ & $292 \cdot 8$ & $145 \cdot 6-442 \cdot 4$ & -7.029 & 0.023 & & & & & 0.615 & 0.881 & & \\
\hline \multicolumn{15}{|l|}{ Oils } \\
\hline Fat in $\% \mathrm{E}$ & $5 \cdot 3$ & $3.4-8.7$ & $5 \cdot 2$ & $2.7-6.9$ & -0.426 & $<0.001$ & 0.038 & $<0.001$ & & & 0.045 & 0.436 & & \\
\hline$g / d$ & $15 \cdot 2$ & $9 \cdot 4-24 \cdot 6$ & $14 \cdot 7$ & $7 \cdot 5-21 \cdot 3$ & -0.939 & 0.021 & 0.077 & 0.041 & & & 0.722 & $<0.001$ & & \\
\hline \multicolumn{15}{|l|}{ Meat } \\
\hline Fat in \%E & 5.9 & $3.8-9.7$ & 5.6 & $3 \cdot 2-9 \cdot 0$ & 0.001 & 0.982 & & & & & 0.019 & 0.816 & & \\
\hline $\mathrm{g} / \mathrm{d}$ & $103 \cdot 1$ & $57 \cdot 2-146 \cdot 9$ & 90.6 & $59 \cdot 2-142 \cdot 1$ & 0.392 & 0.622 & & & & & 3.006 & 0.007 & & \\
\hline \multicolumn{15}{|l|}{ Fish } \\
\hline Fat in $\% \mathrm{E}$ & 0.0 & $0.0-0.2$ & 0.0 & $0.0-0.7$ & 0.026 & 0.025 & & & & & 0.012 & 0.496 & & \\
\hline $\mathrm{g} / \mathrm{d}$ & 0.0 & $0.0-18 \cdot 7$ & 0.0 & $0.0-32 \cdot 7$ & 1.720 & 0.007 & -0.012 & 0.040 & & & 0.667 & 0.149 & & \\
\hline \multicolumn{15}{|l|}{ Nuts } \\
\hline Fat in $\% E$ & 0.0 & $0.0-0.6$ & 0.0 & $0.0-0.0$ & -0.011 & 0.316 & & & & & 0.007 & 0.698 & & \\
\hline $\mathrm{g} / \mathrm{d}$ & 0.0 & $0.0-2 \cdot 7$ & 0.0 & $0.0-0.0$ & -0.023 & 0.688 & & & & & 0.022 & 0.825 & & \\
\hline \multicolumn{15}{|l|}{ Candy } \\
\hline Fat in $\% E$ & 5.5 & $2 \cdot 8-9.0$ & $5 \cdot 1$ & $2 \cdot 3-9 \cdot 1$ & -0.007 & 0.896 & & & & & 2.084 & 0.109 & -0.083 & 0.048 \\
\hline$g / d$ & $82 \cdot 7$ & $51 \cdot 0-148 \cdot 0$ & $73 \cdot 7$ & $44.4-103.5$ & -0.542 & 0.431 & & & & & 44.434 & 0.026 & -1.612 & 0.012 \\
\hline \multicolumn{15}{|l|}{ Sauces } \\
\hline Fat in \%E & 0.2 & $0.0-1.4$ & 0.3 & $0.0-1.6$ & 0.023 & 0.205 & & & & & 0.076 & 0.006 & & \\
\hline$g / d$ & $6 \cdot 7$ & $1 \cdot 9-20 \cdot 8$ & $12 \cdot 4$ & $4.4-28.7$ & 0.313 & 0.396 & & & & & 1.269 & 0.034 & & \\
\hline \multicolumn{15}{|l|}{$\mathrm{CF}$} \\
\hline Fat in $\% E$ & 0.1 & $0.0-2.9$ & 1.9 & $0 \cdot 0-4 \cdot 2$ & 0.083 & 0.021 & & & & & 0.159 & 0.005 & & \\
\hline$g / d$ & $18 \cdot 3$ & $0.0-86.8$ & $50 \cdot 0$ & $0.4-140 \cdot 1$ & 12.665 & $<0.001$ & -1.034 & 0.003 & & & $6 \cdot 127$ & $<0.001$ & & \\
\hline
\end{tabular}

$\% \mathrm{E}$ fat, percentage of total energy intake derived from fat; $\mathrm{CF}$, convenience and fast foods.

${ }^{*}$ Results of a mixed linear model analysing linear, quadratic and cubic time trends. 
in \%E from SFA, but constant intake levels of MUFA and PUFA. SFA intake in 2010 still exceeded the recommendations in more than $90 \%$ of the sample.

In contrast to the present analysis, an earlier examination of the DONALD Study pointed to a more relevant reduction in total fat intake in children and adolescents between 1985 and $2000^{(17)}$. During this time, total fat intake decreased by about $0 \cdot 2 \% \mathrm{E}$ per annum in all the age groups. The combined results from both DONALD examinations are in line with those of a secondary analysis of two German representative crosssectional surveys that were carried out in 1985 and 2006. Stahl et $a{ }^{(18)}$ observed that the median values of fat intake decreased from $37-39 \% \mathrm{E}$ in 1985 to $32-34 \% \mathrm{E}$ in 2006 in German children and adolescents. However, these two cross-sectional surveys do not permit to draw a conclusion as to whether total fat intake declined steadily. The present results indicate that the beneficial trend observed between 1985 and 2000 in the DONALD Study was attenuated in the following decade.

In accordance with the small changes in total fat intake between 2000 and 2010, there were also only a few relevant changes in food intake in $\% \mathrm{E}$ from fat. The observed linear decline in fat consumption from fats and oils was attenuated by positive quadratic trends in subjects between 4 and 18 years. In contrast, between 1985 and 2000, the intake of fats and oils in the DONALD Study decreased linearly by $0 \cdot 2 \%$ E per annum ${ }^{(17)}$. Furthermore, fat intake from milk products (\%E from fat) decreased slightly between 2000 and 2010, but not in the previous 15 years. However, absolute intakes of milk did not decrease uniformly in all the age groups in the study sample. A replacement of full-fat milk products with reduced-fat milk products between 2000 and 2010 might be a possible explanation for decreasing fat intakes from milk. An earlier analysis of the DONALD Study data has already shown an increase in the percentage of low-fat milk products consumed ${ }^{(19)}$. A replacement of full-fat milk, at least partly, by reduced-fat milk, resulting in decreasing energy intake from milk in 2-16-year-old children between 1995 and 2007, was also observed in nationwide Australian dietary surveys ${ }^{(20)}$. In contrast to the present results, Stahl et $a l .^{(18)}$ found that lower absolute amounts of milk and dairy products were consumed by German children in 2006 compared with those who consumed 20 years earlier. According to national dietary surveys from 1999 and 2007, the intake of milk and milk products has also decreased in 3-14-year-old French children, but not in 15-17-year-old French adolescents $^{(21)}$. Despite the observed declines in fat intake from milk products and fats/oils in the DONALD Study between 2000 and 2010, total fat intake remained nearly unchanged as fat intake from convenience foods and fast food increased in the youngest children and in adolescents and fat intake from sauces increased in children between 4 and 12 years. The intake of food groups known to provide a high fat quality, e.g. fish and nuts, has remained at a very low level from the beginning of the DONALD Study.

Besides the results reported by Stahl et al. ${ }^{(18)}$, statistical analyses of changes in fat quantity and quality in children's diet in Western countries after the year 2000 are rare.
By simply comparing cross-sectional data from the National Health and Nutrition Examination Surveys (NHANES) between 2001 and 2006, the US Dietary Guidelines Advisory Committee noticed a constant mean fat intake of about $33 \% \mathrm{E}$ in subjects aged above 2 years ${ }^{(1)}$, but these findings do not focus on children's food intake. A comparison of data from the National Diet and Nutrition Surveys (NDNS) from 1997 and 2008/9 revealed no significant changes in the fat intake $(\% \mathrm{E})$ of children and adolescents in the $\mathrm{UK}^{(22)}$. In contrast, upward time trends in dietary fat intake between 1991 and 2009 have recently been found in Chinese children and adolescents ${ }^{(23)}$, perhaps as an adaptation to a Western lifestyle. Despite this trend, a mean fat intake of $30 \% \mathrm{E}$ in 2009 is relatively low in comparison with that observed in Western countries.

For the end of the last century, information on trends in fat intake is more detailed. Findings in US children and adolescents $^{(24,25)}$ are in accordance with the development demonstrated by earlier results from the DONALD Study. Nicklas et al. ${ }^{(24)}$ statistically analysed cross-sectional data from the Bogalusa Heart Study between 1973 and 1987 and found a linear decline in total fat intake $(\mathrm{g}$ and $\% \mathrm{E}$ ) in 10-year-old US children. This finding seems to reflect a nationwide trend as the dietary fat intake of US children and adolescents declined from $36-37 \% \mathrm{E}$ in the NHANES I (1976-89) to $33-34 \% \mathrm{E}$ in NHANES III $(1988-94)^{(25)}$. In contrast, Moreno et $a l .{ }^{(26)}$ reported that fat intake increased in the 1980 s and 1990 s in Spanish children. However, the relevance of these findings is limited, given differences in the study design of the underlying surveys (e.g. comparison of local surveys with nationwide ones), a wide range of total fat intake at the end of the examined time period $(38-48 \% \mathrm{E})$ and missing information on the statistical relevance of the reported changes in fat intake.

In the present analysis, median fat intake ranged between 33.6 and $34.4 \% \mathrm{E}$ in 2010. Harika et al. ${ }^{(9)}$ have recently reviewed children's dietary fat intake in thirty countries using information from national dietary surveys. Due to differences in data assessment and in the age groups evaluated, a comparison of dietary fat intakes between these countries was difficult. However, results indicated that children's mean dietary fat intake ranged from 32 to $35 \% \mathrm{E}$ in most European countries (e.g. Austria, Denmark, Finland, France, Germany, Hungary, Ireland, Italy and the Netherlands). An analysis of data from the HELENA study revealed a mean total fat intake of about $33 \% \mathrm{E}$ in adolescents across Europe ${ }^{(10)}$. The present values are well within these observed ranges and in accordance with the median values reported by Stahl et al. in $2006^{(18)}$. Since the median fat intake in children in the DONALD Study was at the upper end of the recommendations $(<35 \% \mathrm{E})$, there does not seem to be an acute need for general reductions.

As in the DONALD Study, in US children, a smaller proportion met the recommendations for SFA compared with those for total $\mathrm{fat}^{(25)}$. In the DONALD Study, the SFA intake of more than $95 \%$ of our sample exceeded the recommendations in 2010. Although we found slight reductions in SFA intake in some age groups between 2000 and 2010, these changes were relatively small in comparison with the declines that were 
observed between 1985 and 2000 in the DONALD Study ${ }^{(17)}$. These findings are in line with the results reported by Stahl et $a{ }^{(18)}{ }^{(18}$, who observed decreasing SFA intakes in German children, but not in adolescents. Data from the NDNS also showed slight decreases in SFA intake between 1997 and 2008/9 in children and adolescents in the UK. However, mean intakes were still above the recommendations in every age group ${ }^{(22)}$. As NHANES data indicate a stable mean SFA intake of $11-12 \% \mathrm{E}$ between 1991 and 2006 in subjects aged above 2 years $^{(1)}$, one might argue that policies to further reduce SFA intake have only been marginally effective, if at all, in Western countries.

The development in the UK might be a positive example for Western countries since data showed slight increases in MUFA intake in children and adolescents between 1997 and 2006 ${ }^{(22)}$. Apparently, MUFA partly replaced SFA in the diet of children in the UK, indicating a small improvement in fat quality. In our sample, we did not observe an increase in MUFA intake from 2000 onwards, and between 1985 and 2000, MUFA intake even decreased in children and adolescents in the DONALD Study ${ }^{(17)}$. However, the median MUFA intake in the DONALD Study in 2010 was still higher than the values in the UK. In Germany, an improvement in the PUFA intake in children should be a primary aim since the present results did not show any significant increases in PUFA intake in children, and even initial decreases in adolescents, even though this trend did not last after 2005. This suggests that trends observed in earlier time periods in the DONALD Study partly persisted, as PUFA intake did not increase then either ${ }^{(17)}$. As a consequence, median PUFA intake in 2010 was still well below the recommended $7 \% \mathrm{E}$ in all the age groups. In accordance with the decreasing PUFA intake trends observed in the DONALD Study adolescents between 2000 and 2005, Stahl et al. ${ }^{(18)}$ observed slight decreases in PUFA intake in German adolescents, but also in children. Taken together, both the present results and the results reported by Stahl et $a l{ }^{(18)}$ suggest an ongoing suboptimal fat quality in German children and adolescents characterised by a too high SFA intake and a too low PUFA intake without relevant improvements since the 1980s.

In the DONALD Study, the median intake of SFA ranged between $14 \cdot 2$ and $15 \cdot 2 \% \mathrm{E}$ and that of PUFA ranged from 4.5 to $5 \cdot 3 \% \mathrm{E}$ in 2010 and were thus similar to the intakes of SFA $(12 \cdot 3-16 \% \mathrm{E})$ and PUFA $(3 \cdot 5-6 \cdot 8 \% \mathrm{E})$ in children and adolescents in most of the other European countries ${ }^{(9)}$. The mean intake in European adolescents in the HELENA study was about $13 \cdot 8 \% \mathrm{E}$ for SFA and $4 \cdot 4-4.8 \% \mathrm{E}$ for $\mathrm{PUFA}^{(10)}$. The NDNS also revealed similar mean values of $13.6 \% \mathrm{E}$ $(12.8 \% \mathrm{E})$ for SFA intake in children (adolescents) in the UK in $2008 / 9^{(22)}$. Therefore, it might be hypothesised that not only the cross-sectional intakes, but also the time trends observed in the DONALD Study might reflect general tendencies in the fat quantity and quality of the diets of European children and adolescents.

Considering the present findings on time trends in the fat intake of German children and adolescents, it seems reasonable that future dietary policies should no longer focus solely on reductions in total fat intake, but should also focus on the improvement in fat quality by replacing SFA with PUFA. The Optimized Mixed Diet concept as an example for a food-based dietary guideline recommends regular consumption of foods with a high fat quality (e.g. fish once per week), moderate consumption of meat and the usage of rapeseed oil $^{(27,28)}$. This concept seems to be one promising approach for a sustainable improvement in children's dietary fat quality. However, the increasing time trends observed for convenience and fast foods demonstrate the responsibility of the food industry to improve the fatty acid pattern of food products for children and adolescents as part of an environmental intervention.

Not only some strengths but also limitations of the DONALD Study should be mentioned. Two important strengths are the open cohort design of the DONALD Study, which enables the separation of time trends from age trends, and the usage of constant methods for data assessment. Furthermore, data on dietary behaviour were derived from $3 \mathrm{~d}$ dietary records, which are known to be the 'gold standard' of dietary assessment methods. However, dietary data were self-reported and might, therefore, be limited by under-reporting. Even though we excluded implausible dietary records, our findings might still be influenced by selective under-reporting of 'unhealthy' food groups. The elaborate design of the DONALD Study results in a relatively small study sample, which is not representative with respect to socio-economic status and parental educational level $^{(29)}$. However, earlier analyses of the DONALD Study have revealed no or only minor differences in dietary habits in comparison with a nationwide German dietary survey from 1987 to $1988^{(30,31)}$. Furthermore, recent analyses of nationwide surveys have indicated similar fat intakes in comparison with the present results ${ }^{(18)}$. Therefore, changes in dietary behaviour in DONALD participants might reflect general tendencies in children and adolescents in Germany.

\section{Conclusion}

Fat quantity and quality did not change substantially between 2000 and 2010 in our sample of German children and adolescents. Since a large proportion of our children and adolescents did not meet the recommendations for SFA and PUFA intakes, the main focus of public health programmes should no longer be a reduction in fat quantity, but an improvement in fat quality. It seems obvious that food-based dietary guidelines that recommend the consumption of foods with a more favourable fatty acid pattern should be promoted more intensively. However, given the effectiveness of environmental interventions, the present results are also an appeal to the food industry to optimise the fatty acid pattern of its products.

\section{Acknowledgements}

The DONALD Study is funded by the Ministry of Science and Research of North Rhine Westphalia, Germany. We are very grateful to the DONALD staff for carrying out the anthropometric measurements and for collecting and coding the dietary records. 
The contributions of the authors were as follows: L. L. conducted the statistical analyses; L. L. and U. A. wrote the manuscript; M. K. supervised the study; all the three authors contributed to the interpretation of the data and revision of the manuscript; M. K. had full access to all the data in the study and responsibility for the integrity of the data and the accuracy of the data analysis. The authors declare no conflict of interest.

\section{References}

1. Dietary Guidelines Advisory Committee (2010) Report of the Dietary Guidelines Advisory Committee on the Dietary Guidelines for Americans, 2010, to the Secretary of Agriculture and the Secretary of Health and Human Services. Washington, DC: Government Printing Office.

2. Jakobsen MU, O'Reilly EJ, Heitmann BL, et al. (2009) Major types of dietary fat and risk of coronary heart disease: a pooled analysis of 11 cohort studies. Am J Clin Nutr 89 1425-1432.

3. Mozaffarian D (2011) The great fat debate: taking the focus off of saturated fat. J Am Diet Assoc 111, 665-666.

4. Lapinleimu H, Viikari J, Jokinen E, et al. (1995) Prospective randomised trial in 1062 infants of diet low in saturated fat and cholesterol. Lancet 345, 471-476.

5. Van Horn L, Obarzanek E, Barton BA, et al. (2003) A summary of results of the Dietary Intervention Study in Children (DISC): lessons learned. Prog Cardiovasc Nurs 18, 28-41.

6. Deutsche Gesellschaft für Ernährung (2001) Referenzwerte für die Nährstoffzufubr (Reference Values for Nutrient Intake). Frankfurt am Main: Umschau/Braus.

7. United States Department of Agriculture (2010) Dietary guidelines for Americans, 2010. http://www.cnpp.usda.gov/DGAs 2010-PolicyDocument.htm (accessed 26 July 2010).

8. EFSA Panel on Dietetic Products, Nutrition and Allergies (NDA) (2010) Scientific opinion on dietary reference values for fats, including saturated fatty acids, polyunsaturated fatty acids, monounsaturated fatty acids, trans fatty acids, and cholesterol. EFSA J 8, 1461.

9. Harika RK, Cosgrove MC, Osendarp SJ, et al. (2011) Fatty acid intakes of children and adolescents are not in line with the dietary intake recommendations for future cardiovascular health: a systematic review of dietary intake data from thirty countries. BrJ Nutr 106, 307-316.

10. Vyncke KE, Libuda L, De Vriendt T, et al. (2012) Dietary fatty acid intake, its food sources and determinants in European adolescents: the HELENA (Healthy Lifestyle in Europe by Nutrition in Adolescence) Study. Br J Nutr 108, 2261-2273.

11. Cheng G, Libuda L, Karaolis-Danckert N, et al. (2010) Trends in dietary carbohydrate quality during puberty from 1988 to 2007: a cause for concern? Br J Nutr 104, 1375-1383.

12. Kroke A, Manz F, Kersting M, et al. (2004) The DONALD Study. History, current status and future perspectives. Eur J Nutr 43, 45-54.

13. Schofield WN (1985) Predicting basal metabolic rate, new standards and review of previous work. Hum Nutr Clin Nutr 39, Suppl. 1, 5-41.

14. Sichert-Hellert W, Kersting M \& Schoch G (1998) Underreporting of energy intake in 1 to 18 year old German children and adolescents. Z Ernabrungswiss 37, 242-251.
15. Sichert-Hellert W, Kersting M, Chahda C, et al. (2007) German food composition database for dietary evaluations in children and adolescents. J Food Comp Anal 20, 63-70.

16. Chanmugam P, Guthrie JF, Cecilio S, et al. (2003) Did fat intake in the United States really decline between 1989-1991 and 1994-1996? J Am Diet Assoc 103, 867-872.

17. Alexy U, Sichert-Hellert W \& Kersting M (2002) Fifteen-year time trends in energy and macronutrient intake in German children and adolescents: results of the DONALD study. Br J Nutr 87, 595-604.

18. Stahl A, Vohmann C, Richter A, et al. (2009) Changes in food and nutrient intake of 6- to 17-year-old Germans between the 1980s and 2006. Public Health Nutr 12, 1912-1923.

19. Alexy U \& Kersting M (2003) Time trends in the consumption of dairy foods in German children and adolescents. Eur J Clin Nutr 57, 1331-1337.

20. Rangan AM, Kwan JS, Louie JC, et al. (2011) Changes in core food intake among Australian children between 1995 and 2007. Eur J Clin Nutr 65, 1201-1210.

21. Lioret S, Dubuisson C, Dufour A, et al. (2010) Trends in food intake in French children from 1999 to 2007: results from the INCA (etude Individuelle Nationale des Consommations Alimentaires) dietary surveys. Br J Nutr 103, 585-601.

22. Pot GK, Prynne CJ, Roberts C, et al. (2012) National Diet and Nutrition Survey: fat and fatty acid intake from the first year of the rolling programme and comparison with previous surveys. Br J Nutr 107, 405-415

23. Cui Z \& Dibley MJ (2012) Trends in dietary energy, fat, carbohydrate and protein intake in Chinese children and adolescents from 1991 to 2009. Br J Nutr 108, 1292-1299.

24. Nicklas TA, Webber LS, Srinivasan SR, et al. (1993) Secular trends in dietary intakes and cardiovascular risk factors of 10-y-old children: the Bogalusa Heart Study (1973-1988). Am J Clin Nutr 57, 930-937.

25. Troiano RP, Briefel RR, Carroll MD, et al. (2000) Energy and fat intakes of children and adolescents in the United States: data from the National Health and Nutrition Examination Surveys. Am J Clin Nutr 72, Suppl. 5, 1343S-1353S.

26. Moreno LA, Sarria A, Lazaro A, et al. (2000) Dietary fat intake and body mass index in Spanish children. Am J Clin Nutr $\mathbf{7 2 ,}$ Suppl. 5, 1399S-1403S.

27. Kersting M, Alexy U \& Clausen K (2005) Using the concept of food based dietary guidelines to develop an optimized mixed diet (OMD) for German children and adolescents. J Pediatr Gastroenterol Nutr 40, 301-308.

28. Alexy U, Clausen K \& Kersting M (2008) Die Ernährung gesunder Kinder und Jugendlicher nach dem Konzept der Optimierten Mischkost (The diet of healthy children and adolescents according to the concept of the optimized mixed diet). Ernäbrungsumschau 3, 168-177 (in German).

29. Kersting M, Sichert-Hellert W, Lausen B, et al. (1998) Energy intake of 1 to 18 year old German children and adolescents. $Z$ Ernabrungswiss 37, 47-55.

30. Kersting M, Sichert-Hellert W, Alexy U, et al. (1998) Macronutrient intake of 1 to 18 year old German children and adolescents. Z Ernabrungswiss 37, 252-259.

31. Alexy U, Kersting M, Sichert-Hellert W, et al. (1999) Macronutrient intake of 3- to 36-month-old German infants and children: results of the DONALD Study. Dortmund Nutritional and Anthropometric Longitudinally Designed Study. Ann Nutr Metab 43, 14-22. 